\title{
Perceptions on Impacts of Competition of Eucalypt Plantations with Other Land Uses on the Rural Livelihood in the Western Gurage Watersheds, Central-South Ethiopia
}

Belay Zerga ( $\sim$ belay.zerga@aau.edu.et)

Addis Ababa University

Bikila Warkineh

Addis Ababa University

Demel Teketay

Botswana University of Agriculture and Natural Resources

Muluneh Woldetsadik

Addis Ababa University

\section{Research Article}

Keywords: Eucalypt Plantations, Land Use Competition, Coping Strategies, Perceptions, Impacts

Posted Date: July 12th, 2021

DOI: https://doi.org/10.21203/rs.3.rs-656730/v1

License: (c) (i) This work is licensed under a Creative Commons Attribution 4.0 International License.

Read Full License 


\section{Abstract}

Since recent years, conversions of croplands, grasslands or cash crop fields to eucalypt plantations are becoming common trends in Ethiopia. Reasons for the conversions are better return from eucalypt than crop farming. This study tried to assess the land use competition impacts of eucalypt plantations with other land uses in the Western Gurage Watersheds, Central-south Ethiopia. The specific objectives were to investigate households' and experts' perceptions on land use competition of eucalypt plantations; and to assess perceptions on impacts of eucalypt plantation and copping strategies. Samples from three woredas (districts) namely Cheha, Enemorna Ener, and Eza located in the Watersheds were used. These woredas were purposefully selected due to large coverage of the watersheds, extensive expansion of eucalypts farming and thereby high eucalypts pole production, incidences of serious competition of eucalypts with other uses, and the presences of road accessibility for data collection. To get detail information on perception of the households and experts, in-depth discussions with focus groups and key informant were employed. Individual farm households whose age were greater than 70 years old and knowledgeable persons to discuss on the issue of eucalypt plantations were selected purposefully with the guidance of each kebele (sub-district) chairpersons and district experts. Thereafter, three focus group discussions with farm households were conducted in the three districts. Key informant interviews were conducted with purposefully selected and well experienced individual farm households and experts in each district. The result showed that young farmers planted from 1000 to 5000 eucalypt seedlings on lands previously covered with crops. The young people resisted advice from elders and converted farmlands to eucalypt plantations. Previous practitioners (adoptees) who benefitted much from eucalypt products tended for further expansion. This, in turn, resulted in serious land use competition with farmland and grasslands. To mitigate such serious competition with food crops and grasslands, and to sustain the livelihood and environment, appropriate management, e.g. site selection and substitutions by horticultural and cash crops using micro irrigation schemes for market needs are recommended. Conducting in-depth participatory research and specific policy ratification and promulgation on eucalypt plantations will curb its serious land use competition with farm and grazing lands.

\section{Introduction}

Rural landscapes, particularly those close to human settlements and main roads, throughout the highlands of Ethiopia appear greener than the outfields because of eucalypt farm forests. A number of factors motivate farmers to plant eucalypt trees although the factors vary from site to site based on ecological and socio-economic circumstances. The most common factors for planting eucalypts are two: wood scarcity both for construction and fuel wood and, thus, the need to satisfy household subsistence demand, and to generate cash income. In some communities, eucalypt trees are regarded as a living bank account or insurance resource or life savior, since they can be cut and readily converted to cash during critical needs $[1,2,3]$. In other communities, such as in the Gurage Zone, planting eucalypt is a privilege and obligation of all households not only for meeting household wood requirements and generate cash revenues, but to preserve social pride and reputation $[3,4]$. These reputations depend very much on the 
size of the woodlots. Scarcity of natural forests to provide wood for construction and fuel, and the high opportunity cost of using cow dung and crop residue as substitute for energy makes plantings of fastgrowing species, principally eucalypts, a commendable response in most places throughout the highlands of Ethiopia. Today, in many places, own grown eucalypt wood covers most of the construction wood needs of households and constitutes a substantial part of fuel wood consumptions $[5,3,6]$. For instance, $45 \%$ of interviewed households in Chemoga watershed in Gojjam estimated that between 75 and $100 \%$ of their demand for fuel wood is met by privately planted trees; while a further $20 \%$ indicated that these trees meet $50-75 \%$ of their fuel wood needs [5].

Eucalypts, being resilient species to successfully establish on marginal sites, such as degraded and erosion prone grounds, like gully banks, inside gullies as well as on farmlands that lost crop production potential, stand as the best choice to make economic uses of marginal lands [7,5]. Establishment of eucalypt trees, therefore, appears to be the last in an agro-ecological succession of land-use types, which also suggest that eucalypts are often planted in areas too degraded for crop production [5 8]. While making economic uses of such marginal lands, eucalypts also reduce landslide and soil erosion, and in some cases, eucalypt woodlots are established for land reclamation purposes on plots that otherwise cannot support the growth of other vegetation [3].

Often, farmers grow eucalypts on lands that have little other use options, such as farm boundary (demarcation of farm plots), on degraded parts of their land holdings or in small woodlots at the front yard or in gardens. In some cases, and since recent years, however, conversions of croplands, enset or coffee fields to eucalypts are becoming common $[2,8]$. Reasons for conversion are better return from eucalypt than crop farming $[5,8]$. This implies that households determine their land use selection based on potential benefits and costs given their environmental and economic resource endowments.

In central Ethiopia, Wirtu [9] also showed a Net Present Value from eucalypt cultivation to range from $11,945-74,9665$ Birr/ha (based on soil conditions), which in all cases is 10-fold greater than the return from different agricultural crops, such as barley and wheat. Other studies by Mesfin [10] from Wollo, Teshome [11] and Asnake [12] from Gondar and Kebebew [13] from Shewa all reported similar findings. The above studies confirmed that even if eucalypt woodlots do not offer cash income annually on the same stand, like agricultural crops, the average cash income from growing eucalypts is greater over the rotation than agricultural production.

In Ethiopia, socio-economic evaluations of eucalypts have been carried out, mainly on $E$. globulus and $E$. camaldulensis. The results showed that planting the eucalypts made a substantial contribution to the income of household, more than agricultural crops, especially where the indigenous woodland was degraded and the people were suffering from fuel shortages, water scarcity, erosion and land degradation $[9,14,15,1,16,13,17,18]$. Eucalypt plantations in the country expanded from state-owned plantations to community woodlots and household compounds while in the degraded and drier parts of the country, they have become the principal means of livelihood. Asnake [12] reported that, on average, at least $26 \%$ of the total family income comes from such plantations. 
In Ethiopia, eucalypt species played and will play a tremendous role in alleviating the fuel and construction material needs $[1,18]$. In some areas, planting Eucalyptus globulus overrides food crop yields and makes returns to land 1.3-1.7 times and returns to labor 1.2-1.5 times greater than in single wheat cropping [19]. The other great positive contribution of eucalypt is replacing indigenous species for firewood, thereby, preventing further denudation of natural forests [20].

In planted areas, eucalypts trees are the (largest) non-agricultural sources of household income [15, 21]. Similarly, Kebebew and Ayele [22] argued that assigning $12 \%$ of the land to eucalypts can increase the household income from the land by up to $90 \%$ and reversely substituting the eucalypts covered land by important crops, such as teff and barley may reduce the income from the land by up to $125 \%$. In general, practicing eucalypt planting as one land use besides cultivating other crops in the available field could improve the household income and contribute to poverty reduction effort in Ethiopia. This study investigated the socioeconomic impacts of eucalypt plantations in Western Gurage Watersheds located in Central-South Ethiopia. The specific objectives were to investigate perceptions of households and experts on land use competition of eucalypt plantations and assess perceptions on impacts of eucalypt plantation and copping strategies.

\section{Research Methods 2.1. Study Area}

The Gurage Zone is located in Central-south Ethiopia with the location between $7^{0} 40^{\prime}$ to $8^{0} 30^{\prime}$ North and $37^{0} 30^{\prime}$ to $38^{\circ} 40^{\prime}$ East and covers an area of $5,932 \mathrm{~km}^{2}$. The Administrative Zone is bordered by Oromia Region in the west, north and east, Yem Special Woreda (District) in the southwest, Hadiya Zone in the south and Silti Zone in the east. The Gurage Zone consists of thirteen woredas and topographically, the area lies within an elevation ranging from 1,000 to $3,638 \mathrm{~m}$ above the sea level. The highest point of the area is Mt. Zebidar. The climate of Gurage Zone is affected by the altitudinal gradients. The four traditional agro-ecological zones (AEZs), namely afro-alpine (wurch), temperate (dega), sub-tropical (woina-dega) and tropical (kolla) are found in the Zone. However, woina dega is the dominant one. The average temperature ranges from $<3^{\circ} \mathrm{C}$ (in) the Gurage mountain chains to $28^{\circ} \mathrm{C}$ in the Ghibe River Gorge. The annual range of rainfall is between 600 in the rift valley (East Gurageland) and 1,900 $\mathrm{mm}$ in the highlands. The ranges of agro-ecologies have enabled the area to grow different types of crops, such as enset [Ensete ventricosum (Welw.) Cheeseman] (hereafter referred to as enset), cereals, pulses, oil seeds, vegetables and fruits as well as support livestock, including sheep, goat and pack animals. Different wild animals and birds inhabit the area owing to such climatic diversity.

As noted by Woldetsadik [23], soil colors in the enset growing areas, like Gurage Zone, range from brown and black to red. Two of the soil groups, Pellic Vertisols and Euric Nitsols, are most common and cover more than $60 \%$ of the region. Depending upon the population pressure and local farming systems, Vertisols are intensively cultivated and mostly devoted to grain production in the dega (high plateaus). However, they are left largely for grazing in the low plateaus, the lower woina-dega and the upper kolla 
sections of the Zone. Based on the 2007 census conducted by the Central Statistical Agency (CSA) [24] of Ethiopia, the area is inhabited by a total population of 1,279,646 in 2005 and expected to be about 1, 919469 of whom $49 \%$ are male and $51 \%$ are female. Accordingly, the Zone has a population density of greater than 450 person's $\mathrm{km}^{-2}$. About $9.36 \%$ of them are urban inhabitants and the remaining are rural dwellers. Gurage Zone is one of the most densely populated areas in Ethiopia. High population pressure and a long history of settlement have resulted in an increasing quest for agricultural land, wood for farmhouse construction, fuel and other uses. This, in turn, has resulted in the degradation of the natural forests and shrubs found along river valleys [25].

Gurage Zone is divided by four drainage basins, namely Awash, Rift Valley, Bilate and Omo-Gibe [26]. Except for minor deviations at the local level, the streams in the area have a dendrite drainage pattern. The direction of flow of the streams may vary depending upon orientation of local relief at micro level. However, all the major streams ultimately drain to west and south-west/east ward, following the general inclination of the slope direction of the Zone. The Western Gurageland (Watersheds) drains to Omo-Gibe Basin and cover large areas. In the western parts of Gurageland, several rivers and streams drain from northeast and east to west that is to Gibe River. The major riveris Gibe with its tributaries such as Wabe, Winike, Megecha, Rebu, Zizat, Gogare and Dire rivers. These rivers have several tributaries that emerge from the chains of Gurage Mountains located in the northeast and east, and join at different locations. The rivers, Winike, Gogare and (Derie) are the largest rivers next to Wabe River, and altogether cover an area of 173,476 ha (Fig. 1).

From these, the main watershed is Winike, which includes Megecha and Zizat rivers and covers an area of 117,030 ha. The Gogare and Drie watersheds cover an area of 30,739 and 25,707 ha, respectively.

The five districts of Gurage Zone, i.e. Eza, Cheha, Gumer, Geta and Enemorna Ener, are found in these watersheds. These areas share many physical features. These watersheds were selected due to their dense population and large coverage of eucalypts tree plantations.

\subsection{Secondary Data}

To get clear understanding of the concepts, such as expansion and competition of eucalypts, income diversification and livelihood support, secondary data from published sources were reviewed critically. In this part exclusion and inclusion approach, selecting and retrieving the appropriate and recent literature were undertaken. Thereafter, the final report (findings) was analyzed and synthesized to show and fill the research gap.

\subsection{Primary Data}

\subsubsection{Sampling Method}

As reported by CSA [24] the study area, Gurage Zone, has thirteen Woredas (Districts) with a population of $1,279,646$ people $(1279646 * 0.5=1919469)$. For the purpose of the study, samples from three woredas 
located within Western Watersheds of Gurage Zone were collected. The selected woredas were Cheha, Enemorna Ener and Eza. These woredas were purposefully selected due to large coverage of the watersheds, large coverage and expansion of eucalypt tree farming and, thereby, high eucalypt pole production, incidences of serious competition of eucalyptus with other land uses, and the presence of road accessibility for data collection. Thus, these woredas were considered as representatives of eucalypt plantation activities in the area.

To get detail information from perception of the households and experts, in-depth discussions with focus groups, and key informant interviews were employed. Heads of individual farm households whose ages were more than 70 years old and other knowledgeable persons were pooled to discuss about the eucalypt plantations, reasons for its expansion and conversion of crop land to eucalypt woodlots. They were selected purposefully with the guidance of Kebele chairpersons and district experts. Thereafter, three focus group discussions with heads of farm households were conducted in the three districts. Each group included six to eight members. The discussions were guided by facilitators, and group members were encouraged to talk freely on raised topics. Key informant interviews were conducted with purposefully selected and well experienced heads of individual farm households and agricultural experts in each district. Hence, a total of nine key informants were selected from nine sample Kebeles of the three districts. Important professional key informant interviews were employed with six agricultural and natural resources experts from the three districts (two experts from each). Moreover, interviews with Agricultural Development Agents (DAs) and kebele chairpersons were administered. In each district, individual interviews and informal communications with eucalypt pole traders and brokers (middlemen) were also conducted. From all the focus group discussions and interviews, valuable information was gathered by the principal researcher and assistants with the help of voice recording devise and smart phone camera. After transcribing the audio documents into written words, translation from the local language to English was made. The discussions were complemented by field observations and various actual field photos.

\subsubsection{Method of Data Analysis}

The survey data were analyzed using explanatory qualitative techniques. Thus, to describe the data acquired from critical observations, focus group discussions, key informants' interviews, critical and logical qualitative descriptive data analysis techniques were used.

\section{Results And Discussion}

\subsection{Perceptions of Households on Eucalypt Plantations 3.1.1. Reflections on History of Introduction of Eucalyptus to their Localities}

As reported in the focus group discussions in Azerna Sise kebele of Cheha Woreda), participants asserted that Fitawrari Habtegiorgis Dinegde (the then Governor of Southwest Shewa, including Gurage area) 
introduced the species to Debregent Jato Kidus Giorgis area around 1890's. This is articulated by all kebeles and supported by reports [25]. Abagada Bekena Chegen, an experienced elder of 93 years old from Moche Kebele of Cheha Woreda reported that his father started planting eucalypt trees around 1910. Particularly, eucalypts expanded after 1950's. Many individuals planted more than one thousand seedlings in the 1970's after a local chief named Kegnazmach Amerga who introduced many eucalyptus tree seeds from Menagesha. In a similar manner, eucalypt tree plantations expanded to many other localities of Gurage areas by the respective local chiefs. Thereafter, farmers started planting on their possessions to benefit from the multiple uses of eucalypts (due to their advantages).

\subsubsection{Reflections on Competition of Eucalypts}

The responses of the focus group discussants and key informants revealed that eucalypt tree lots expanded because of its multiple uses, which include for fuel wood, construction, market, environmental conservation, enhancing favorable micro-climatic conditions, scenic value and shade for humans and animals. The first three are the main reasons. Based on income generated from eucalypts, households raise their children as well as pay school fees, land taxes and other social expenses. As reported in the focus group discussions in Azerna Sise (Cheha Woreda), when some households plant and cut eucalypt trees in adjacent farm boundary of the neighborhood, they removed perennials like mango, avocado, papaya, and others that are important cash generating crops. Such practices were in conflict with other land uses and caused quarrel among neighborhoods.

In another scenario when farmers passed away, their land possessions are mostly transferred to their children (living in urban areas). Children finally convert the transferred lands to eucalypt woodlots (Fig. 2), mainly, for tenure security. After initial plantation task, they generated continuous cash without closer management need.

Previous households (practitioners) which benefitted much from eucalypt products are attributable for further expansion by others. White eucalypt (Eucalyptus globulus Labill) is confined to highland parts whereas red eucalypt (Eucalyptus camaldulensis Dehnh) species are more grown in the lowland areas. Households use leaves of the white eucalypt used to cure from cold and flu fever and bronchial illness and to remove ants at home. However, in terms of beauty and strength the red eucalypt is better, and it is also less affected by termites. The former is fast growing, volatile and much preferable for fuel wood than the later. Poles are transported to urban areas mainly to Addis Ababa for construction purposes and raw materials for furniture and manufacturing asbestos.

In dega (upland) areas, land use competition of eucalypts with croplands is very serious than in woina dega (midland) and kolla (lowland) areas. Water desiccation effect of the eucalypt tree species seems also very serious in these areas. This is because the surplus rainwater gained during the summer (keremt, wet season) season reaches at its critical shortage point in the winter season (bega, dry season ) as a result of probably increased evapotranspiration, percolation and runoff discharge effect. This is accentuated by the water desiccation effect of eucalypt tree plantations, which aggravated water scarcity problem manifested by dry stream courses in many areas. 
Queremeya in Azerna Sise Kebele of Cheha woreda, formerly known for its extensive swampy nature is nowadays transformed to extensive eucalypt woodlots. The fast growing advantage of the species in such water logged sites and the short-term benefits obtained from pole production from eucalypts drive the selection of swampy sites. Similarly, swampy areas, such as Chiche in Worit, Yewaheniye in Shebraden, and Mamude in Zigba Boto Kebeles in Eza woreda have been converted to eucalypt woodlots. There are also many wetlands in Terede Kebele in Enemorna Ener woreda, which have been converted to extensive eucalypt woodlots.

\subsubsection{Reflections on the Land Use Competition of Eucalypt in the area}

The cultural landscapes of the Gurageland in general and the study area in specific are dominated by two new landscape features (trends): one is eucalypt tree lots expansion and the other is replacement of the traditional thatched farm houses increasingly by houses constructed with (aluminum) corrugated iron sheets. When one look the cultural landscape of Gurageland from the panoramic viewpoints (upland areas), the scenic attractions of cultural houses, grass lands and Enset crops are hidden by eucalypts. Since grasslands are converted into eucalypt woodlots and the consequent lack of grass for thatching traditional houses, farmhouses constructed with (aluminum) corrugated roofing sheets are becoming increasingly a common phenomenon. With the passing away of elderly people, care for the cultural Gurageland landscape has been diminishing because of changing land use system. The young farmers planted from 1,000 to 5,000 eucalypt seedlings on lands previously covered by food crops. As reported by focus group discussants, the young generation seems resisting advice from elders owing to their high entrepreneur capacity, which is leading to the conversion farmlands into eucalypt plantations.

The best examples of eucalypts in converting extensive grzing areas are the well-known communal plains of 'Amera Hebir' and 'Ambussie Hebir' in Cheha and Eza Woredas, respectively. These impressive rangelands are connected to each other and were inaccessible during rainy seasons as a result of their marshy nature. However, after recent time, the two extensive plains have been drained by communal and private plantation of eucalypts, and the open areas are converted to investment corridors. Private modern farm projects such as Tinaw Flower and Horticultural farms, and packed water factories like Daki, Wow and Ethio (Tsedey) as well as Government institutions, like Wolkite University have contributed in changing the landscape of the two plains.

Competition with crop and grass lands, water depletion of streams, springs and ponds soil degradation, and undergrowth suppression by eucalypt plantations are well understood by households. However, economic benefits, coppicing, fast growth, non-palatability, less labor demand and tenure security (in terms of management needed) overshadowed farmers to use eucalypt plantations in appropriate sites.

Wild animals use eucalypt plantations as hiding areas after they pass over forests and bushes. Wild animals, such as monkeys, apes, hyenas, wild pigs and eagles are attacking crops and domestic animals and, thereby, threaten the livelihood of households. To this, midland and lowland areas are the most 
vulnerable ones as a result of large coverage of eucalypt plantations, and the presence of remnant community and riverine forests.

The conversion of grassland to eucalypt plantations resulted in shortage of livestock fodder and, hence, reduction of livestock number. The average number of livestock per household decreased astonishingly. Thus, as reported in the focus group discussions, the average number of cows and oxen decreased from 8 to 3 and 3 to 1, respectively; sheep from 10 to 3 , goats from 6 to 2, horses from 2 to 1 , mules from 1 to 0 and donkeys from 2 to 1 .

Accordingly, due to lack of manure, farmers have started using chemical fertilizers even for horticultural crops, including enset that was not practiced before. An elder and experienced key informant farmer, Abagada Bekena Chegen (93), with more than sixty years of planting experience of eucalyptus trees from Moche Kebele of Cheha Woreda, articulated that:

"The natural quality of crop products decreased substantially after farmers started using artificial fertilizers. For instance, the local potatoes named 'Eroge' and 'Abesha', which were very tasty, rich in nutrition and contributed to food security, have disappeared recently and changed by high breed ones, which have lower quality, and are toxic and not tasty. The quality of milk and its byproducts has substantially decreased due to the toxic effect of eucalypt litter that falls on grasslands in which animals are feeding".

\subsubsection{Measures Taken to Moderate Eucalypt Competition with Crops and Grazing Lands}

The best land use decision and allocation is to plant eucalypt trees in marginal lands that are not utilizable (suitable) for crop cultivation. As reported by focus group discussants, young farmers may not stop eucalypt tree planting on croplands unless they are compensated with improved fruits, vegetables, cash crops or other alternatives at least for income substitution. However, substituting eucalypts by other species for fuel wood and construction materials seems very challenging in the near future.

As reported by one of the experienced and educated farmers, Merkeb Asefa Sira, living in Worit rural Kebele of Eza Woreda, the competition of eucalypt trees was initially with bushlands and private grazing land, followed by grasslands and, then, annual croplands and enset plantations. He strengthened his ideas by emphasizing that "eucalypts are not expansive species by themselves; however, people irresponsibly expand them". Hence, the recent rational view of blaming the management than eucalypt itself is very substantial. Thus, the remedies to its competition reside on proper management.

In each Kebele, there are two government assigned local authorities. One is the kebele leader, locally known as "yekebele likemenber" (Chairperson of kebele), and, mostly, he works closely with farmers. The other one is kebele manager, locally named as "yekebele sira askiage" who is, mostly, assigned as government controlling agent. These authorities do not support small farm holders concerning land use management. Their major task is executing government duties and regulations as well as playing a role 
as a political bridge between farm households and Woreda- level government agents. They strive to report, such cases to district managers without caring for land use conversion (Fig. 4).

\subsubsection{Measures to Be Taken to Reduce the Adverse Impacts of Eucalypt Trees}

The water stress effect of eucalypt is well understood by farmers. However, short-term incomes gained from the species, their fast growth and high coppicing ability also overshadowed their opportunity to plant them on ideal site that is far away from croplands, streams, ponds and wetlands. Even though Development Agents (DAs) advise farmers to plant eucalypt trees wisely at appropriate sites, young farmers resist their advice by being stimulated from its short-term reward. As reported by well experienced elder Abazinab Chehawork Chapesye (91), with more than sixty years of experience in planting eucalypts from Moche Kebele (Cheha Woreda), elder farmers started planting on unproductive areas. They have resisted shifting eucalypts to flat lands for fear of their adverse effects.

To curb the adverse impacts of eucalypt trees, farmers have to confine planting the tree in rugged areas (badlands) that are far away from croplands. Grassland areas also should not be converted to eucalypts since the number of livestock is diminishing due to scarcity of fodder (Fig. 5). Mixing eucalypt tree planting with other indigenous trees would decrease the water depletion and land degradation threat of smallholder farmlands, and communal land possessions that are very vital in terms of multidimensional ecosystem services. However, farmers are overshadowed by the short-term return gained from the eucalypt tree species, and they convert their (flat) lands that are suitable for food crops to eucalypt woodlots.

According to a well experienced key informant, Damo Gebre Balo (89), and with more than sixty year experience in planting eucalypts from Azerna Sise Kebele in Cheha Woreda, "when the elders advise the young farmers to plant eucalypts in appropriate sites, they refuse to do so, and request for other ways of substituting the species if they have to drop planting of eucalypts." He strengthened his surprise by indicating that the youth are excited by the income generated from planting eucalypts. He also reported that when large possession of his landholding was divided among his brothers who are living in towns, they allotted their land holdings to eucalypt woodlots. This is because they are living in urban areas and did not want to invest in the management of crop farming. Their other motives were seeking of short-term reward and tenure security.

The number of DAs working in the areas is not enough to provide professional services to all village households found in the kebeles. Particularly, natural resource professionals are too few or absent in many kebeles. As reported by the well experienced farmer, Ato Nesru Ibrahim, Chairperson of Azerna Sise Kebele of Cheha Woreda, "conducting research on eucalypts is too late. It would have been beneficial had it been conducted prior to the transformation of our croplands and grasslands to eucalypt woodlots". 
Banning eucalypt seedling propagation and distribution to minimize its expansion was effective in government and NGOs nursery sites. However, individual farmers are not prohibited from such activities. As reported by focus groups, some farmers propagate from 5,000 to 10,000 seedlings per year to sell and use for themselves. Their farmlands are converted to eucalypt woodlots by allowing some area for enset based agroforestry. In other scenario, farmers' main reason of planting eucalypts on flat lands, instead of rugged topography, is attributable to transport accessibility and crop production failure.

As reported by key informants, they are participating in watershed management campaign to save private and communal lands from degradation and erosion. Previously, they were planting eucalypts for recovery of eroded land. However, after they have been informed not to use eucalypts for this purpose by DAs due to its adverse effect, they stopped using eucalypts and replaced them by other indigenous trees and fast growing non-invasive exotics.

\subsubsection{Households' Perceptions on Consultation they received from DAs}

As reported by key informants and focus groups, DAs support farmers. They are visiting farm plots, mainly, to distribute fertilizers during farming seasons. They support youth farm associations than smallholder farmers. DAs reported that farmers resist accepting advice and new technologies. When experts blame farmers' resistance to accepting new ideas and technologies, it is equally prudent to interrogate the appropriateness of services and supervision skills of DAs'. DAs have to also accept values of farmers' indigenous knowledge before pushing them to use modern farming methods and technologies. Accordingly, farmers' indigenous knowledge should be harmonized with modern ideas and technologies for sustainability of interventions.

Many farmers in the midland areas partly transformed their cereal and pulse crops farming to eucalypt farming by leaving some space for enset, vegetables, and homestead perennials, such as coffee, chat [Catha edulis (Vahl) Forssk. Ex Endl.] and fruits. As noted before, such decision of farmers is attributable to high income generated from the eucalypt species. Boundary plantations of eucalypts are common, mainly in dega areas, and these are creating conflicts among neighbors due to the adverse impacts on crops grown in border areas.

If this trend is not curtailed in short time span by experts and other stakeholders with involvement of the community members, the livelihood sustenance of many community members shall be at risk, and they would not be able to produce enough food crops. In similar scenario the Gurage farming system and cultural landscape will be transformed from enset-based mixed farming system to another new system. This possible risk was expressed by the key informant, 91 years old Abazinab Chehawork Chapesye, in Moche Kebele of Cheha Woreda by saying, "the rural Gurage shall leave his birth place and migrate to other area". Hence, with the presence of diminutive land holding size and high population pressure, other alternatives, including eucalypt plantations, may not substitute the food security status of enset. If one has the money generated from diverse sources including selling eucalypt trees he/she can buy food crops produced by others from elsewhere. However, money generated from eucalypt products may not 
substitute enset in sustaining households' food security due to price deflation which is noticeable in the country after near past..

\subsection{Experts' Opinion on Eucalypt Tree Plantations 3.2.1. Awareness and Experience on Eucalypt Plantations}

As reported by experts (Fig. 6) they have enough awareness about eucalypts. They are well informed that famers adapted this species due to its fast growth and coppicing nature and to use it, mainly, for fuel wood, construction and income generation purposes. They are aware that farmers converted their croplands to eucalypt plantations due to failure in crop production and high income generated from selling poles within four to six years. As reported by Ginbaru Hailemariam, with twenty-five years of experience expert in crop production in Cheha Woreda, "farmers have enough knowledge in eucalypt tree farming and expansion, and they are involved in eucalypt plantation activities, mainly, for obtaining fire wood, construction material and selling. Other pull factors are due to its less labor and management requirement, fast growth, non-palatability by livestock, ability to ensure tenure security, amelioration of local microclimate, scenic and shade values".

The DAs have reported that they have enough awareness on the competition of eucalypts with croplands, including enset and grasslands. Hence, they give advisory services to farmers to plant eucalypts not on lands that are suitable for crop cultivation, but rather shift tree planting to marginal and abandoned lands that are already not suitable for cropping. As they reported, some farmers started charging each other when they are planting on adjacent boundaries of the other possessions for fear of its adverse effect on their crops and grasslands.

Asefa Biru, an expert of natural resources management with more than twenty-five years work experience, alluded that "we advise farmers to avoid planting on boundaries with adjacent cropland of neighboring household possessions. We advise farmers to target ideal site selection for planting eucalypt trees". It was reported in one locality, named Neshe which is located in Eza Woreda, that when farmers were planting thousands of eucalypt tree seedlings on communal grazing land, they were forced to stop planting and remove the seedlings. In recent years, plantations of species of Pinus and Cupressus, which have similar adverse environmental effects like eucalypts, are expanding around homesteads and farm boundaries. Farmers plant these species for generating income. Ibrahim Hussen, who is a member of the top management group in Eza Woreda with more than eighteen years of work experience in the area, indicated that "This time we are witnessing an invasion of the Gurage Zone by eucalypt tree plantations". He also said that the young generation has to fight unwise land use, planting and expansion of eucalypt trees, in order to use the land sustainably. He concluded by saying "I have participated in many meetings and conferences in this Woreda, but I have never seen any issue raised concerning the threat caused by eucalypt plantations". According to Arega Gami, an expert in crop production with thirty-five years of experience in Eza Woreda, surprising enough, some agricultural professionals who have their own private landholdings have planted eucalypt trees on croplands contrary to becoming a role model to farmers by planting the eucalypt trees on ideal sites of marginal land. 


\subsubsection{Attitudes on Merit or Demerit of Eucalypt Plantations}

With regard to dominance of merit and demerit of eucalypt trees, there are two dichotomies among experts. Some experts argue that the merits of eucalypts overweigh the demerits. Experts, who argue that the merits outnumber and overweigh than the demerits support their arguments by referring that eucalypts are fast growing and useful for fire wood, construction, cash generation, raw materials for factories, scenic and aesthetic values, and microclimate modification and provision of shade for humans and animals. Their adverse effects on environment (soil erosion, water depletion, nutrient uptake and land use competition) can be mitigated by employing wise land management on site and species selection, blending, tinning, mixing, pruning elongated branches towards crops and grasslands. They strongly substantiate their argument by saying:

"Farmers started counting lots of money from sale of eucalypt tree poles in a way that have never happened before in their farm history and were able to construct modern houses with roofs of iron corrugated sheets. In addition, they have been economically empowered to buy modern beds and mattresses, clothes for their family, started owning a plot of land in urban areas, pay government taxes, school fees to their children, home expenses as well as social and religious costs".

Households' purpose to plant eucalypt trees is not only for fuel wood and construction needs, but to cover their financial needs. They can minimize its drawbacks by substituting horticultural and cash crops using small scale irrigation schemes since the area are endowed with terrestrial and ground water resources. Hence its merits are higher than its demerits.

On the other hand, experts who believe the demerits of planting eucalypt trees are wide-ranging argued that they have replaced croplands and grasslands. After the establishment of eucalypt trees, replacing the area by croplands and grasslands, which involves removal of their stumps and roots is very difficult by using human labor and requires tractors or bulldozers. Using these machines is unaffordable for most farmers. Litter fall from eucalypt trees reported causing of threat on the adjacent croplands due to possible allelopathic effects. One can easily observe the status of crops sown closer to eucalypt tree species compared with those far away. This was evidenced by the fact that the color of nearby crops looked light green or yellowish whereas those located farther away looked dark green. Accordingly, areas closer to eucalypt trees were reported as being less productive than those far away. Despite the various merits enumerated in favor of eucalypts, they are reported to affect the farming system of the area.

District experts reported that there were government and NGOs nursery sites, which raised and disseminated eucalypt seedlings to farmers before thirty years ago. Some farmers not only benefited much better than others from planting the eucalypt seedlings obtained from the nurseries, but they were also rewarded by government as role models. After learning about land use competition created by eucalypt and their environmental drawbacks, the entire nursery sites were banned from raising eucalypts, and, instead, started propagation of perennials, such as apple, mango, plum and avocado. Thereafter, 
farmers started supplying fruits, like apple, peach and plum to the local markets and Addis Ababa. Thus, with the right management of eucalypt plantations, the two dichotomous concerns will merged into one.

\subsubsection{Perceptions on Opportunities to Mitigate Threat on Eucalypt Trees Expansion}

As reported and agreed by all experts in the sample Woredas, it seems very difficult and impossible to reduce expansion of eucalypt tree plantations in the near future, particularly for firewood and construction needs. This is because finding substitution for it and awareness creation up to local level may take a long time. There is no other tree species, proposed yet, that can substitute eucalypts, particularly for firewood needs. For construction, red ash soil to prepare bricks and stones are proposed. Opportunities forwarded for income generation included cultivating horticultural and cash crops, using small scale irrigation schemes, fattening high breed animals by zero grazing as well as engagement in dairy and poultry farms. For seriousness of mitigating its expansion, "eucalypt tree is termed as a politicized tree" in South American countries [27]. This indicates that its expansion became a contested issue of environmental politics in these countries. Eucalypt trees are widespread and threatening in developing than the developed countries, and there is little attention given to its expansion and serious land use competition in the global political arena. The 1990's "Food for Work Campaign Program" in Ethiopia aggravated expansion of eucalypt on communal lands for the purpose of environmental reclamation and afforestation. In the study area, Ambussie communal eucalypt trees plantation, which is found between Eza and Mihur-Aklil woredas, is a typical example in this regard. It drained approximately one fourth of the wetland of the area. As reported by experts, some training programs were undertaken about the wise land use utilization of smallholders in 2000/2001. However, no awareness creation and training activities concerning the environmental effects of eucalypt trees were offered by experts to farmers until then.

\subsubsection{Reflections on Responsible Bodies for the Expansion of Eucalypt Trees}

All interviewed experts from the sample districts felt that government bodies may be the first and farmers might be the next responsible bodies since the two represent advisors and practitioners, respectively. As they reported, government bodies have to be concerned about the future fate of the land and advice farmers on ideal farm forestry practices, including eucalypt plantations.

Farmers are managers, and they need to be complemented with knowledge and skills that they lack in farm management. Consultations should be targeted at complementing and promoting their best indigenous knowledge. Providing them with new technologies and harmonization of the two (indigenous knowledge and new technologies) should be the win-win strategies. According to Mr. Arega Gami, a crop production expert with thirty-five years of experience, responsible Government bodies are aware of the expansion of eucalypt trees and the unwise planting practices. He questioned the lack of active regulatory measure by the concerned bodies with regard to expansion of eucalypts, especially at 
inappropriate sites. He reiterated that it is not enough to simply collecting tax revenue from eucalypt poles, which seems to ignore the sustainability of the environment and livelihood.

\subsubsection{Perceptions to Substitute Eucalypt Plantations by Other Alternatives}

All experts agreed that so far there is no much progress accomplished in finding substitutes or other alternatives. There are efforts to substitute eucalypt by horticultural crops using small-scale irrigation schemes for market needs. However, substitution of eucalypt trees by other alternatives as source of fuel wood has proved difficult. As reported by experts, in order to minimize the negative impacts, there should be tangible scientific research on matching plantation of eucalypts to appropriate sites. The experts indicated that a wider outlook horizon should be adopted towards the merits and demerits of eucalypt in order to blame the inappropriate management applied rather than eucalypt [1]. There is one promising substitution for lighting and fuel wood in the near future by way of electrification thorough generation of electricity by the hydro dams that are under establishment.

Through community participatory, in-depth research and creating pilot practitioner farmers, it may be possible to substitute eucalypt by horticultural and cash crops for the purpose of diversifying household income. However, substituting them by other alternative for fuel wood, attributed to their fast growth and coppicing superiority, may take a long time. Thus, for market values, fruits and vegetables, such as apple, avocado, mango, plum, cabbage, onion, garlic, potato, tomato, beetroot, salad, carrot, taro and others can be cultivated. Growing cash crops, like coffee and sugarcane, are also recommended using small-scale irrigation. For construction needs, the use of bricks and stones may assist substituting eucalypt poles and wood. Thus, substitution of eucalypt by other alternatives for income generation seems possible and affordable while for others, it will be challenging in the near future.

\section{Conclusions And Recommendations}

\subsection{Conclusions}

Households in the study area plant eucalypt as a primary farm forestry practice, partly, for fuel wood and construction needs. Their contribution in fulfilling financial needs (demand) is sustainable and much better than other agricultural engagements. There is indispensable attachment between the purposes and household needs particularly for fuel wood and construction. Hence, substituting eucalyptus for fuel wood and construction by other alternatives seems very challenging in the near future. The main reasons include fast growth, high coppicing ability in a short time, not being labor and capital intensive, nonpalatability, not being affected by soil, climate change, insects and pests, requiring lower management interventions than crop production and animal rearing as well their multipurpose uses. Another superiority of eucalypt is their attractive prices in the markets due to the booming construction industry and other manufacturing needs in urban areas of the country. 
On the other hand, the competition of eucalypt with other land use; water depletion, particularly streams, springs and ponds; soil and grassland degradation as well as suppression of undergrowth caused by eucalypt are well understood by households. However, economic benefits, fast growth and high coppicing ability, non-palatability, (less labor intensiveness) as well as ensuring tree tenure security are very attractive for the farmers to use eucalypt plantations widely. Eucalypt trees are not expansive species by themselves unless they are intentionally planted by people. Hence, the recent tendency of blaming the management rather than eucalypt has to be properly addressed by the famers and also responsible authorities. The remedy to address the problem of competition of eucalypt with other land uses in the study areas resides on proper management, including appropriate plans for species-site matching [1].

The cultural landscapes of Gurage Zone in general and the study area in particular are currently dominated by two new trends, namely expansion of eucalypt tree lots and booming of houses constructed using iron corrugated roofing sheets. Observation of the cultural landscapes of Gurage Zone from panoramic views (upland areas) clearly reveals that the scenic attractions of cultural houses, grasslands, and enset crops are hidden by eucalypt tree plantations. Since grasslands have been converted to eucalypt woodlots, leading to shortage or lack of grasses to be used for thatching traditional houses, houses constructed with iron corrugated roofing sheets are booming at increasing rates. Associated with the passing away of elders, care for proper land use in the Gurage area is diminishing. This is because the young generations have high entrepreneur capacity and relatively lesser care for environmental sustainability or lack long-term thinking for the value of land. Hence, they convert farmlands into eucalyptus plantations. When and if desired by farmers, removing trees of eucalypt is relatively easy. However, the challenging part is to remove the stumps and roots of cut trees, which might require the use of bulldozer, which is very costly and not affordable by many households.

In the dega (upland) areas, land use competition between eucalypts and croplands is very serious than woina dega (midland) and kolla (lowland) areas. Water consumption by eucalypt trees is high in the area. This is because the surplus rainwater gained during the wet (summer) season reaches at its critical shortage point in the winter season as a result of percolation and discharge effects. Hence, additional water uptake by the eucalypt plantations in the dry (winter) season aggravated the water scarcity problem of these areas.

The incremental trend of income generation from the sale of eucalypt is attributable to their fast growth, availability of road networks, better market facilities and attractive prices. This, in turn, resulted in serious land use competition of eucalypt with farm and grazing lands.

\subsection{Recommendations}

Based on the findings of the study, the following practical and policy recommendations are forwarded.

1. There is the need to advise farmers to confine planting eucalyptus trees to marginal lands than using (flat) croplands; 
2. pruning elongated branches to crop and grasslands and practicing thinning of young trees to reduce their densities as they grow;

3. mixing eucalypt tree plantations with indigenous trees to decrease their adverse effects;

4. removing and using the litter and leaves for fuel wood to minimize undergrowth suppression;

5. banning planting eucalypt trees along farm boundaries to avoid adverse impacts on crop fields and grasslands, and curb conflicts between neighbors;

6. giving training to farmers on ideal land use allocation based on their possession;

7. protecting wetlands and communal grazing lands from encroachment of eucalypt plantations to sustain livestock and water resources of the area;

8. conducting in-depth participatory research to ensure appropriate species-site selection and search for possible substitution of eucalypt species; and

9. develop and implement appropriate policies and legislation on eucalypt plantations.

\section{References}

[12] Asnake A. (2002). Growing performance and economics of growing Eucalyptus camaldulensis by small holder farmers of Amhara Region: the case of Gondar Zuria District, North Gondar, Ethiopia. Ethiopian M.Sc. thesis report 2002:57. Swedish University of Agricultural Sciences, Sweden.

[5] Bewket W. (2003). Household level tree planting and its implications for environmental management in the northwestern Highlands of Ethiopia: a case study in the Chemoga Watershed, Blue Nile basin. Land Degradation and Development, 14: 377-388.

[24] CSA (Central Statistical Authority) (2007). Population and Housing Census, Final Report, Addis Ababa, Ethiopia.

[20] Evans J. (1992). Plantation forestry in the tropics: Tree planting for industrial, social, environmental, and agroforestry purposes. 2ed ed., Oxford Science Publications, Clarendon Press, Oxford, New York.

[7] Gebremedhin B., Pender J. and Tesfay G. (2003). Community natural resource management: the case of woodlots in Northern Ethiopia. Environment and Development Economics, 8: 129-148.

[16] Getahun A. (2002). Eucalyptus farming in Ethiopia: The case for Eucalyptus woodlots in the Amhara region. Conference Proceedings, Ethiopian Society of Soil Science, 137-153.

[17] Holden S., Benin S., Shiferaw B. and Pender J. (2003). Tree planting for poverty reduction in lessfavored areas of the Ethiopian highlands. Small-Scale Forest Economics, Management and Policy, 2(1): 6380.

[15] Jagger P. and Pender J. (2000). The role of trees for sustainable management of less-favored lands: The case of Eucalyptus in Ethiopia. EPTD Discussion paper No. 65. International Food Policy Research Institute, Washington, D. C. USA. 
[27] Jeffrey L. (2007). The Political Ecology of a "Forest Transition": Eucalyptus forestry in the Southern Peruvian Andes, Ethno botany Research \& Applications, 5: 085-093.

[8] Jembere D. (2009). The expansion of Eucalyptus plantation by small holder farmers and its drivers: the case of Arsi Negelle district, southern Oromia Ethiopia. MSc thesis, Hawassa University, Wondo Genet College of Forestry and Natural Resources, Awassa.

[13] Kebebew Z. (2002). Profitability and household income contribution of growing Eucalyptus globulus to smallholder farmers. MSc thesis, Swedish University of Agricultural Sciences, Skinnskatteberg, Sweden.

[22] Kebebew Z. and Ayele G. (2010). Profitability and household income contribution of growing Eucalyptus globules (Labill.) to smallholder farmers: the case of central Highland of Oromia, Ethiopia. European Journal of Applied Science, 2(1): 25-29.

[21] Kelemu K. and Tadesse W. (2010). Analysis of Eucalyptus role in the livelihoods of rural households. In: Gil L, Tadesse W, Tolosana E, López, R, editors. Eucalyptus species management, history, status and trends in Ethiopia. Proceedings of the Congress. Ethiopian Institute of Agricultural Research, Addis Ababa: 53-61.

[19] Kidanu S. (2004). Using Eucalyptus for soil and water conservation on the Highland Vertisols of Ethiopia. PhD Thesis, Wageningen University, The Netherlands.

[10] Mesfin D. (2002). Economic analysis of E. globulus plantation in the former Dessie fuel wood project, South Wollo, Ethiopia. MSc thesis, Swedish University of Agricultural Sciences, Skinnskatteberg, Sweden.

[2] Negash M. (2002). Socio-economic aspects of farmers' Eucalyptus planting practices in the EnsetCoffee based agroforestry system of Sidama, Ethiopia. The case of Awassa and Shebedino Districts. MSc thesis, Swedish University of Agricultural Sciences, Skinnskatteberg, Sweden.

[3] Negussie A. (2004). Farm Forestry decision making strategies of the Guraghe households, SouthernCentral highlands of Ethiopia. PhD Dissertation. Institut fur Internationale Forst-Und Holzwirtschaft Technische Universitat Dresden, Germany.

[26] Sahle M., Fürst C. and Yeshitela K. (2018). Plant diversity analysis for conservation of Afromontane vegetation in socio-ecological mountain landscape of Gurage, South Central Ethiopia, International Journal of Biodiversity and Conservation, 10(4): 161-171

[1] Teketay D. (2000). Facts and experience on eucalypts in Ethiopia and elsewhere: ground for making wise and informed decision. Walia, 21: 25-46.

[11] Teshome M. (2004). Economics of growing E. globulus on farmer's woodlots: the case of Kutaber district, south Wollo, Ethiopia. MSc thesis Report, Hawassa University, Ethiopia. 
[18] Teshome T. (2009). Is Eucalyptus ecologically hazardous tree species? Ethiopian Journal for Research and Innovation Foresight, 1(1): 128-134.

[9] Wirtu D. (1998). The economics of growing E. globulus (labill.) in the highlands of Oromiya, Ethiopia. MSc thesis, Swedish University of Agricultural Sciences, Skinnskatteberg, Sweden.

[14] Wolde-Selassie G. (1998). The forest resources of Ethiopia past and present. Journal of the Ethiopian wildlife and natural history society. 19: 10-28.

[23] Woldetsadik M. (1994). Population Pressure, Land Use Change and Patterns of Agricultural Productivity in Sebat Bet Gurageland. M. A. Thesis Addis Ababa University, Unpublished.

[25] Woldetsadik M. (2003). Impacts of Population Pressure on Land Use/Land Cover Change, Agricultural system and Income Diversification in West Gurageland, Ethiopia. PhD Dissertation, Department of Geography, Faculty of Social Sciences and Technology Management, Norwegian University of Science and Technology, UTNU, Trondheim, Norway.

[6] Zerga B. and Woldetsadik M. (2016). Contribution of Eucalyptus Tree Farming For Rural Livelihood in Eza Wereda, Ethiopia Palgo journal of Agriculture, 3(1): 111-117.

[4] Zerga B. (2016). Extent and causes of Eucalyptus tree Farming expansion in Eza wereda, Ethiopia, Palgo Journal of Agriculture, 3(2): 132-147.

\section{Declarations}

Informants (or legal guardian) consented to participate and/or publish.

\section{Competing interest}

The authors declared there is no competing interest.

\section{Figures}




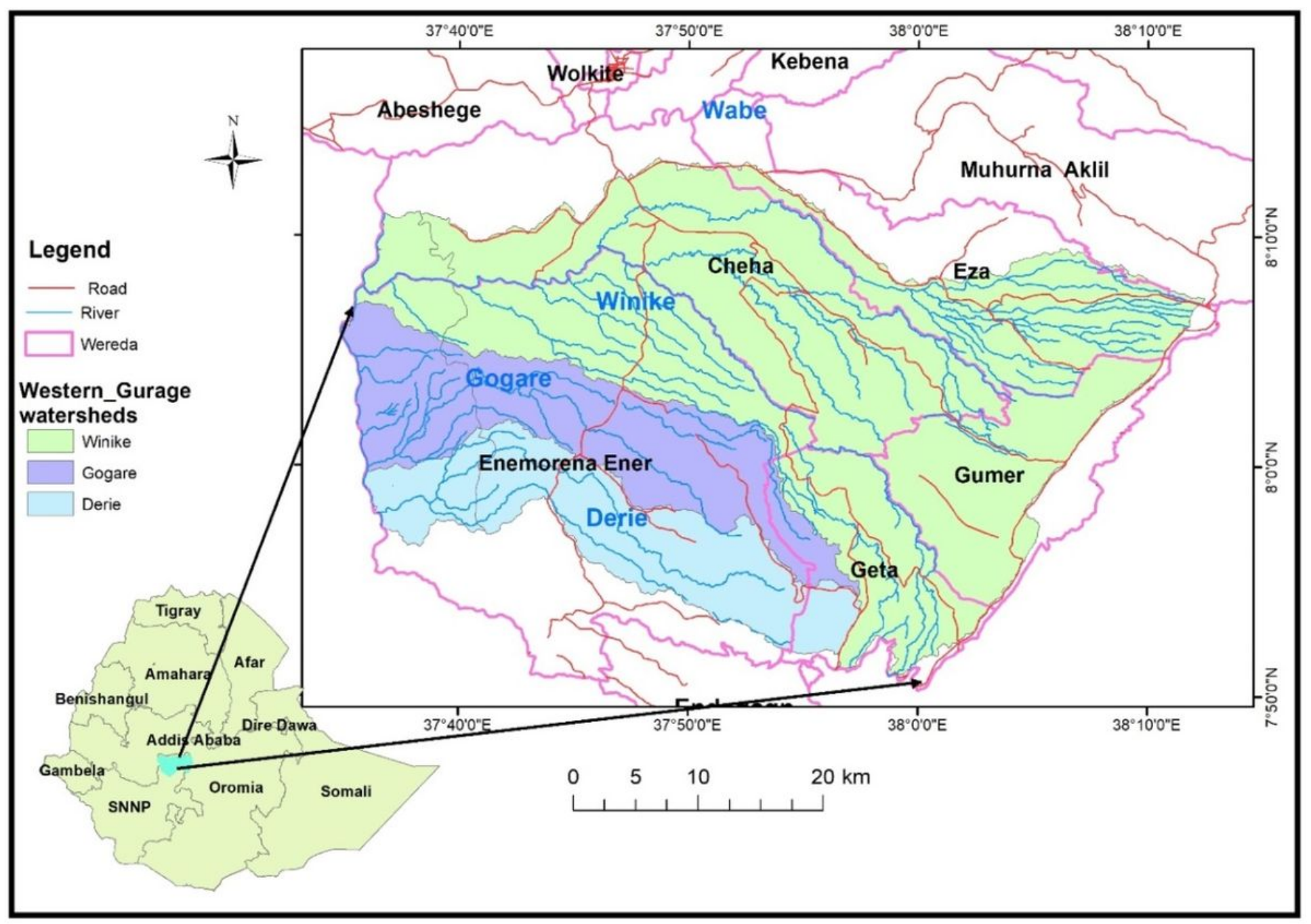

Figure 1

Location map of the Western Gurage Watersheds. 


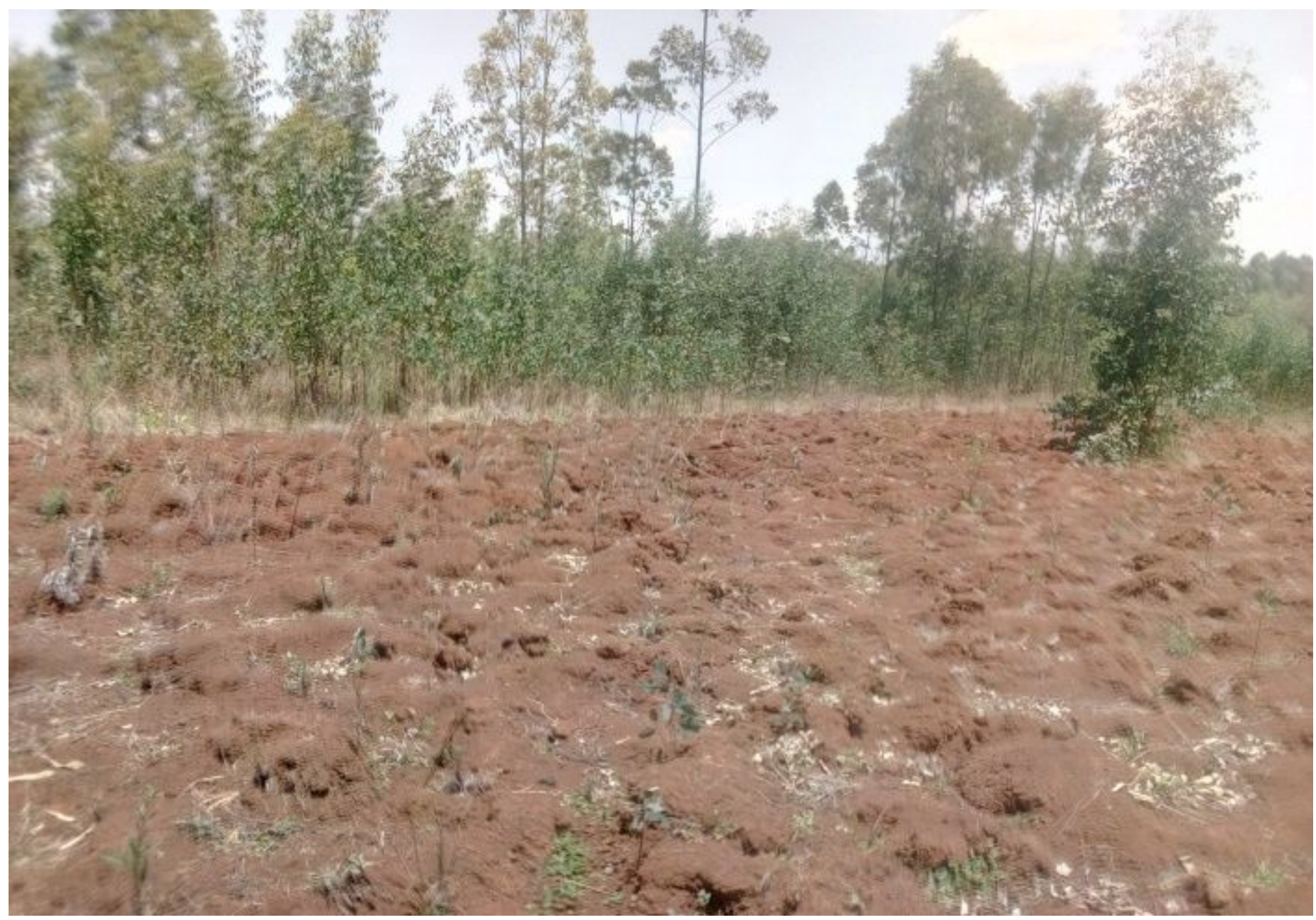

Figure 2

Convention of croplands to eucalypts in Azerna Sise Kebele (Cheha Woreda) (Photo by Belay Zerga, 2017).
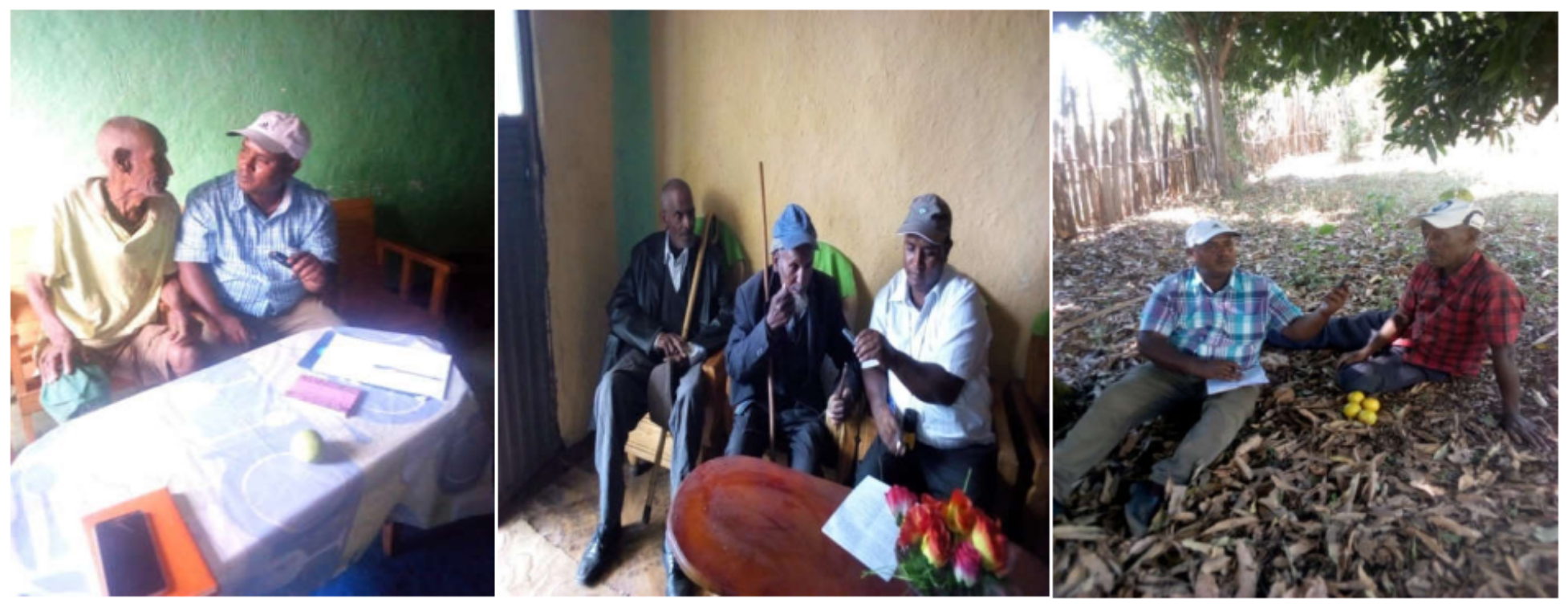

Figure 3 
Key informants' interviews in Azerna Sise and Moche Kebeles (Cheha Woreda) and Zigba Boto Kebele (Eza Woreda) (Photo by Belay Zerga, 2017).

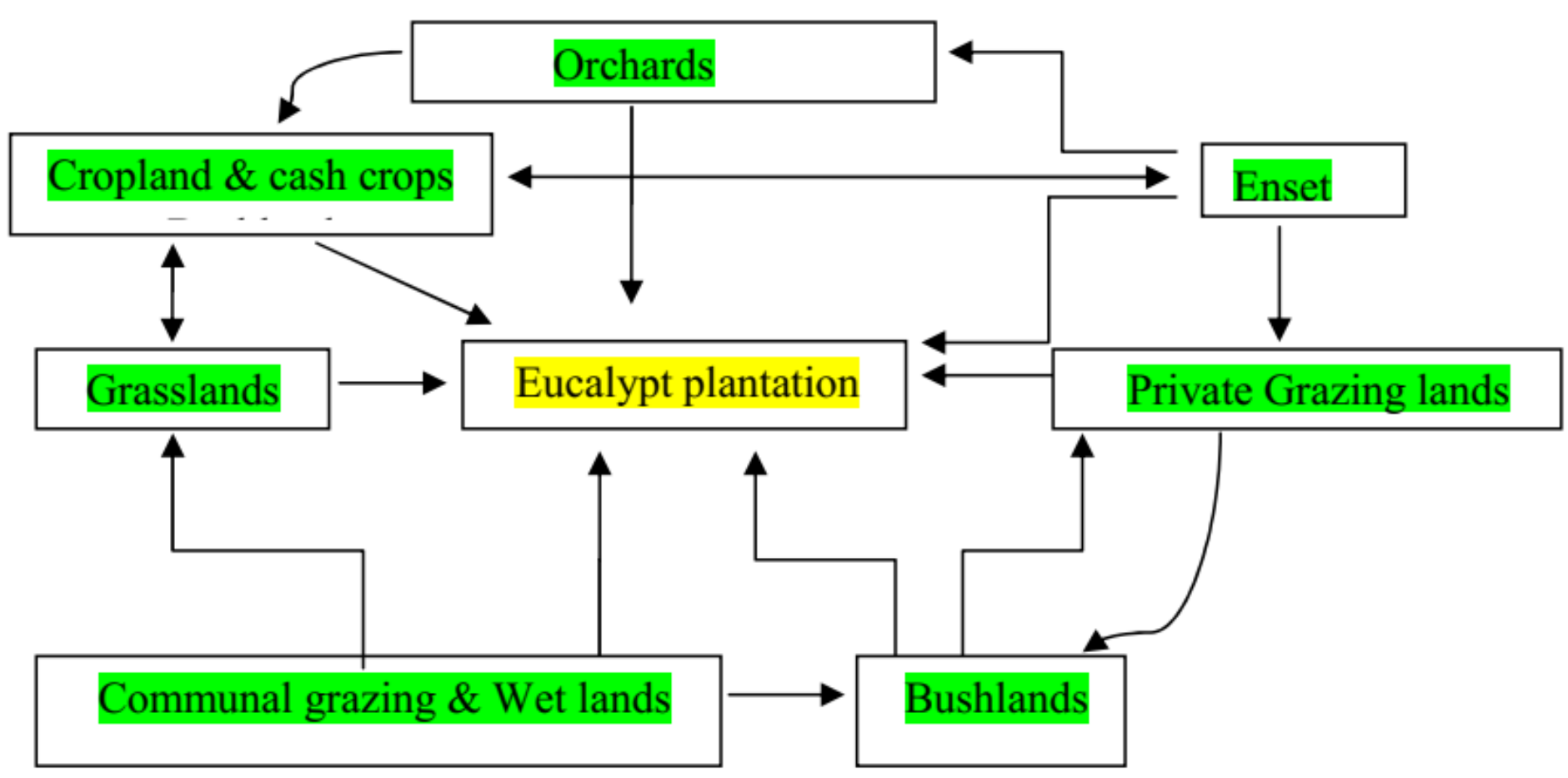

Figure 4

A diagram showing conversion of other land uses to eucalypt plantations (based on personal observation and outcomes of group discussions). 


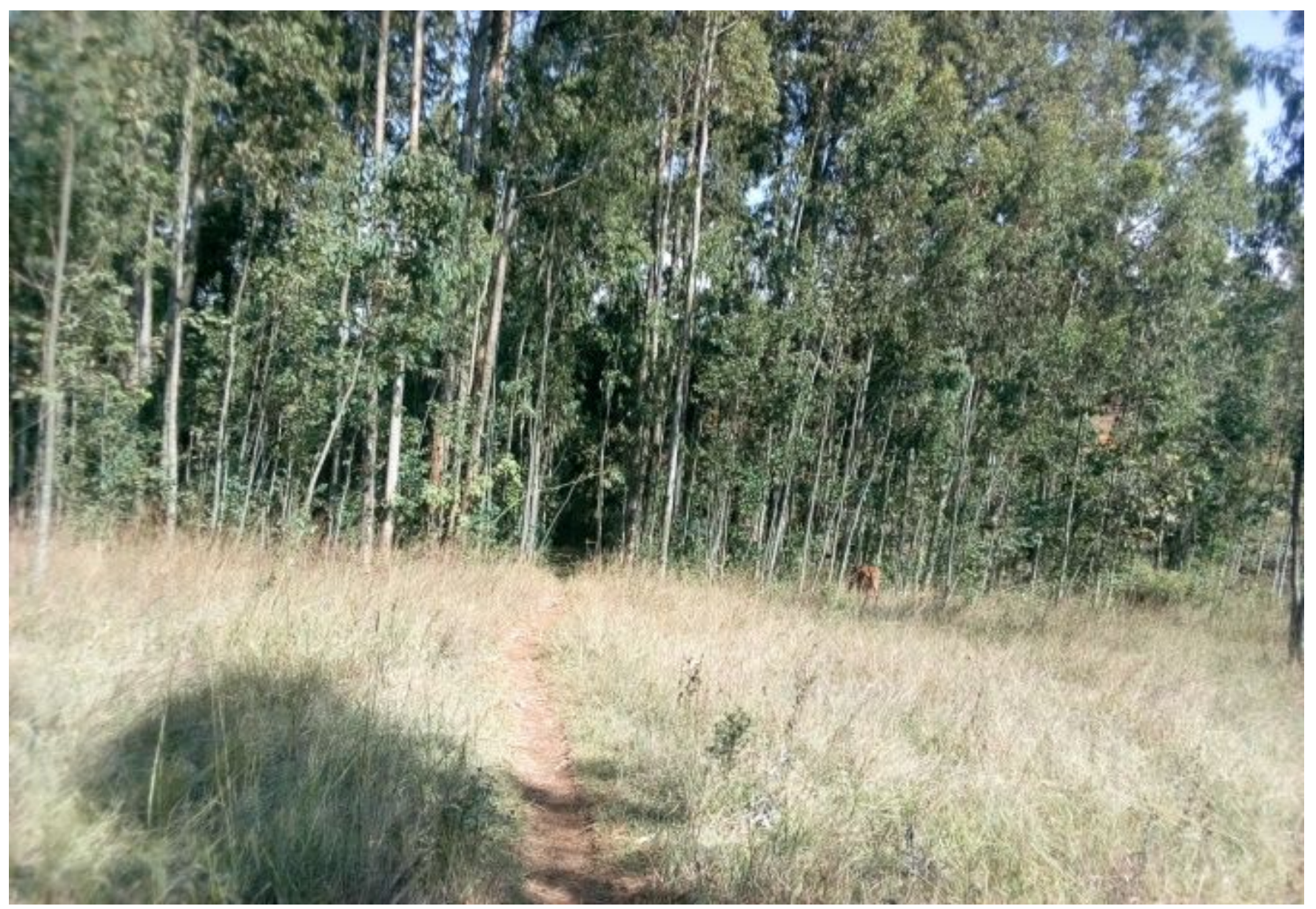

\section{Figure 5}

Conversion of grasslands to eucalypt lots at Azerna Sise Kebele (Cheha Woreda)(Photo by Belay Zerga, 2017).
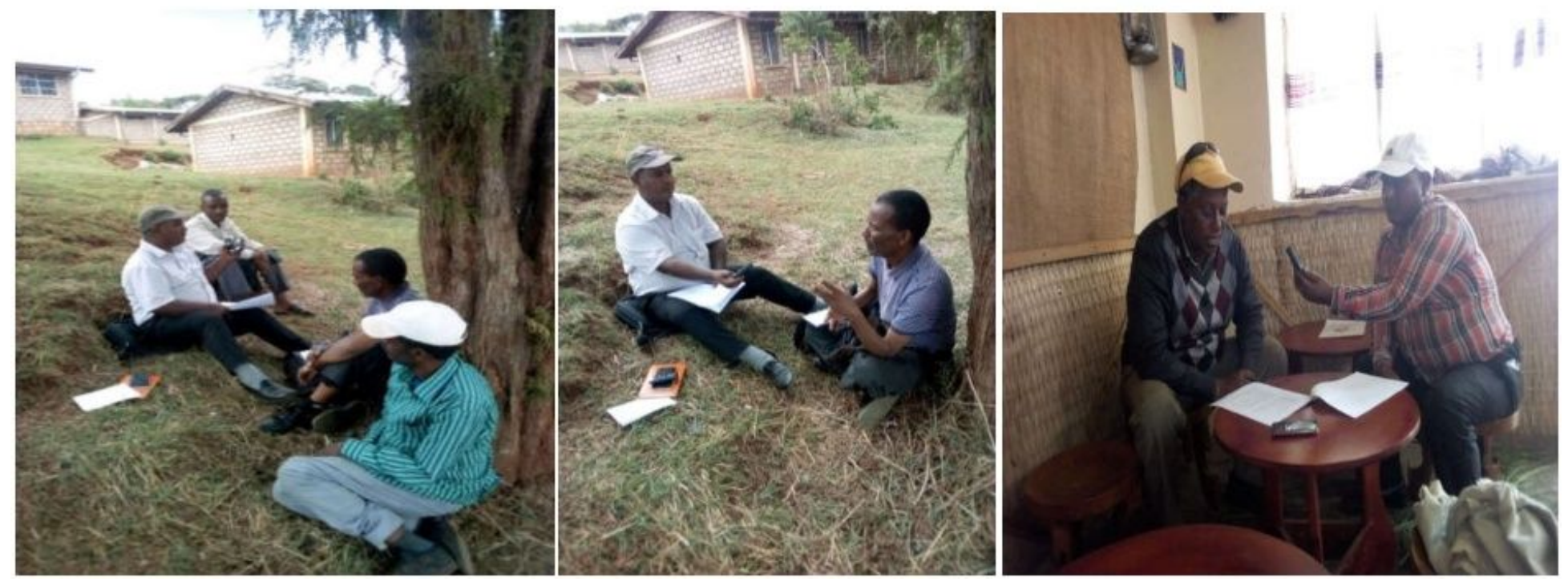

\section{Figure 6}


Key informant experts' interviews at Agena (Eza Woreda) and Emdibir (Cheha Woreda) (Photo by Belay Zerga, 2017).

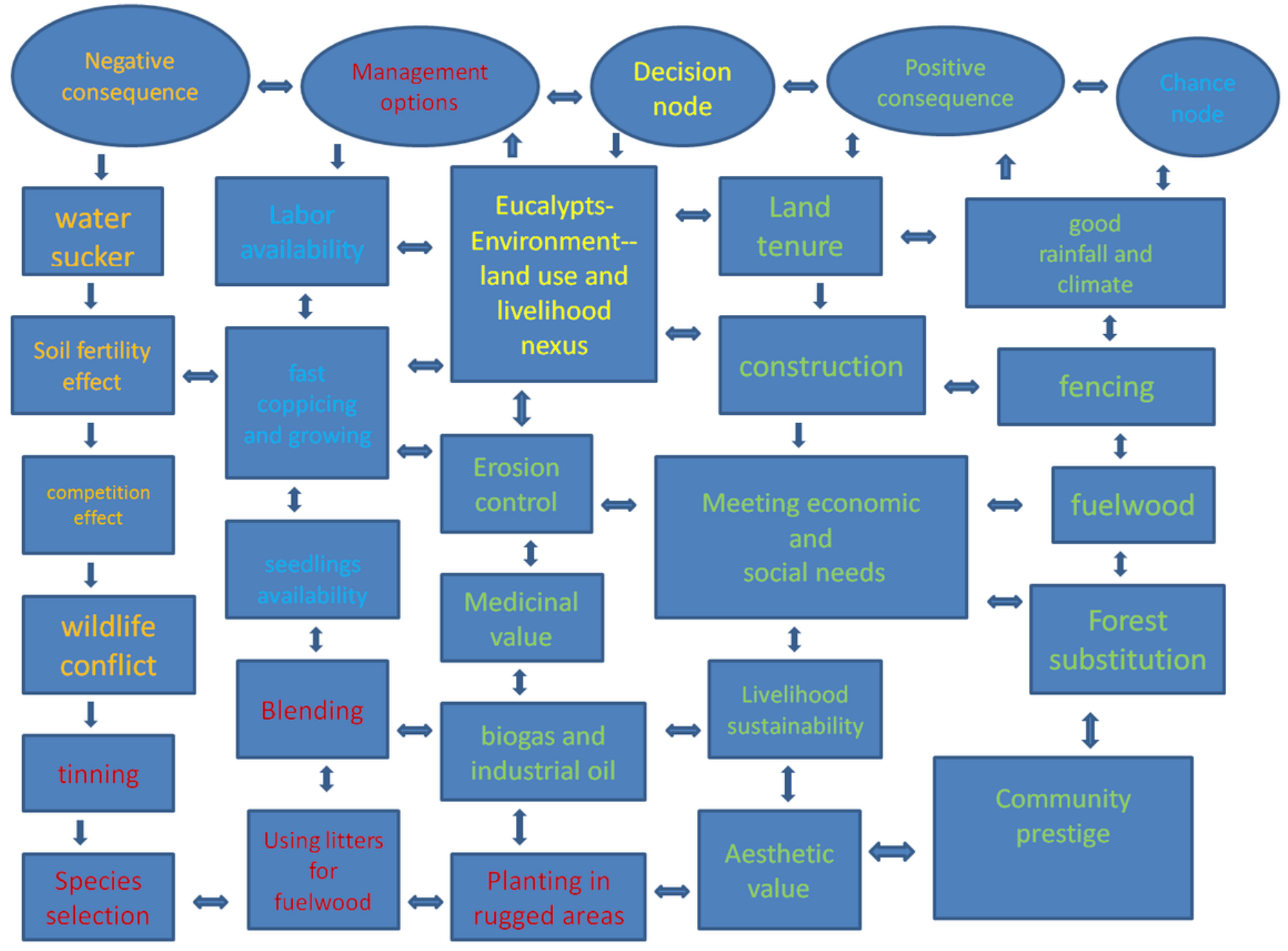

\section{Figure 7}

Eucalypts-Environment-Land use and Livelihood Nexus (Adapted from the findings and [3]. Different rectangular colors represent the top respective circular ballots. 